\title{
Exploring Faculty Perspectives on College-to-University Transfer in a Large Canadian University
}

\author{
Lynne Bowker
}

\section{QUERY SHEET}

This page lists questions we have about your paper. The numbers displayed at left are hyperlinked to the location of the query in your paper.

The title and author names are listed on this sheet as they will be published, both on your paper and on the Table of Contents. Please review and ensure the information is correct and advise us if any changes need to be made. In addition, please review your paper as a whole for typographical and essential corrections.

Your PDF proof has been enabled so that you can comment on the proof directly using Adobe Acrobat. For further information on marking corrections using Acrobat, please visit http://journalauthors.tandf.co.uk/production/acrobat.asp; https://authorservices.taylorandfrancis.com/how-to-correct-proofs-with-adobe/

The CrossRef database (www.crossref.org/) has been used to validate the references. Changes resulting from mismatches are tracked in red font.

\section{AUTHOR QUERIES}

Q1 Please note that the ORCID for Lynne Bowker has been created from information provided through CATS. Please correct if this is inaccurate.

Q2 Please confirm corresponding author details are correct.

Q3 The funding information "the Ontario Council on Articulation and Transfer (ONCAT)" provided has been checked against the Open Funder Registry and we failed to find a match. Please confirm if the Funding section is accurate and also confirm the funder name "the Ontario Council on Articulation and Transfer (ONCAT)".

Q4 Citation [Wheeler, 2019] has been updated. OK?

Q5 Please provide reference for citation [Ontario (2004].

Q6 Please provide missing [City] for the [Khaja, 2013] references list entry. 


\title{
Exploring Faculty Perspectives on College-to-University Transfer in a Large Canadian University
}

\author{
Lynne Bowker \\ School of Information Studies, University of Ottawa, Ottawa, Ontario, Canada
}

\begin{abstract}
Investigations into college-to-university transfers have focused largely on the experiences of students, staff, and college faculty, while relatively little attention has been paid to the perspective of university faculty. This article first reviews the literature, which presents the views that the other stakeholders attribute to university faculty. Next, results from a survey and follow-up interviews conducted with faculty at a large Canadian university are presented. While there is some overlap between the concerns presented indirectly in the literature and the concerns expressed directly in the survey and interviews, there are also areas of divergence. The article concludes by noting that university faculty do have opinions on transfer and that their voices are worth listening to, not least because doing so will allow universities to establish how best to direct their resources to more effectively support a culture of transfer.
\end{abstract}

While student transfer from college to university has been the subject of a growing volume of literature, most of this work focuses on either the policies and administrative issues involved in developing and implementing transfer partnerships between colleges and universities (e.g., Khaja, 2013; Kirby, 2007; McGowan \& Gawley, 2006; Senie, 2016; Wheeler, 2019), or on the transfer students' experience (e.g., Andres, 2001; Arnold, 2011; DeWine, Bresciani Ludvik, Tucker, Mulholland, \& Bracken, 2017; Shaw, Spink, \& Chin-Newman, 2019; Umbach, Tuchmayer, Clayton, \& Smith, 2019). To date, comparatively little attention has been paid to understanding the faculty perspective, although some researchers, such as Landeen et al. who investigated the student experience, have acknowledged that "it is important to understand faculty and staff perceptions of collaborative programs and the students who are enrolled in those programs" (2017, p. 149). Similarly, O’Donnell, Miller, \& Fowler echo "there is little research which examines faculty perspectives regarding pathway students' preparedness although their viewpoints may influence both student access and experience" (2018, p. 4).

Moreover, as noted by Percival et al. (2016), the majority of existing literature focuses on the community college partners, rather than the university partners. Therefore, while O'Donnell et al. (2018) did indeed explore the faculty perspective, their study investigated only the community college faculty who were involved in preparing students for a transfer program. Similarly, Kisker (2007) conducted interviews with both colleges and universities; however, the college interviewees included both administrators and college faculty involved in transfer programs, while on the university side, only administrators were interviewed. Meanwhile, McGowan and Gawley (2006, para. 4) chose deliberately not to include faculty members in their study of the university perspective on the following grounds:

Interviews did not include university faculty because faculty class registration records do not identify which students are college transfer students so unless a student self-identifies as a college transfer student, a student's prior academic involvement is not known to faculty.

CONTACT Lynne Bowker Ibowker@uottawa.ca School of Information Studies, University of Ottawa, 70 Laurier Ave East, Hamelin Building, Ottawa, Ontario, Canada

(C) 2019 Taylor \& Francis Group, LLC 
While the lack of ability to identify specific students as being transfer students might limit a university faculty member's ability to comment directly on transfer student performance, these faculty can still comment on many other aspects of the transfer process, including issues that they see as barriers to developing or delivering articulated programs. Gaining a better understanding of their perspective could lead to a greater level of university faculty buy-in - a factor that is generally considered to be important for transfer to be successful.

A similar lack of attention to the university faculty perspective exists outside of North America too. For instance, Fernández Diaz, Carballo Santaolalla, \& Galán González (2010, p. 102) explain that in Europe, "the main objective of the Bologna Process is to create a European space for higher education that allows for comparability, compatibility and coherence between the existing systems of higher education across Europe" - an objective that is generally referred to as the European Higher Education Area (EHEA). However, as pointed out by Fernández Diaz et al. (2010), "very few existing studies assess faculty attitudes toward the creation of the EHEA" (p. 103) or toward its associated tool the European Credit Transfer and Accumulation System (ECTS).

Both Kisker (2007) and Percival et al. (2016) point to yet another gap: the majority of existing studies are quantitative in nature, focusing on transfer rates, grade point average patterns and withdrawal rates (e.g., Gerhardt \& Masakure, 2016; Stewart \& Martinello, 2012). In contrast, comparatively few studies focus on social-cultural aspects such as detailing lived experiences, and those that do take this approach tend to focus on the student experience, rather than on the faculty experience. Additionally, Kisker (2007) calls for more research into the processes by which collegeuniversity transfer partnerships can be created and sustained, including the identification of factors that may be barriers or aids to achieving such partnerships, such as faculty attitudes, for example.

Given that limited attention has been paid to investigating university faculty, the overarching goal of this article is to gain a deeper understanding of university faculty members' perspectives on transfer, including identifying obstacles to and strategies for engaging faculty in a culture of transfer. Unlike McGowan and Gawley (2006), who chose to exclude faculty members in their study, we believe that even in the absence of being able to identify transfer students on the class roster, faculty members can still offer useful insights into the overall experience of the development and implementation of articulation agreements and transfer between colleges and universities. Moreover, we feel that it is important for other stakeholders, including college faculty, college and university administrators, and transfer students, to be aware of the university faculty perspective since the success of transfer depends on the cooperation of all parties. As a step toward gaining a deeper understanding of the university faculty perspective, we undertook a survey and follow-up interviews with faculty members at the University of Ottawa, one of Canada's oldest and largest universities, who have been or could potentially be involved in designing and implementing articulation agreements between colleges and universities.

This article is organized as follows. We begin with a review of the literature, after which we present an institutional context and discuss the results of a survey and follow-up interviews that were undertaken with university faculty at the University of Ottawa in order to obtain more direct insight into their attitudes and concerns. Interestingly, while there was some correspondence between the concerns reported in the literature and those expressed by survey and interview participants, there were also some divergences. Though data was gathered only from a single institution, this project serves as a useful case study whose findings may inspire similar investigations at, or across, other institutions. Finally, we end with some thoughts and recommendations about the value of consulting university faculty in order to know where to most effectively invest resources for promoting a culture of transfer.

\section{Literature review}

It should be noted that higher education models differ from one region to the next, and this is particularly true with regard to college-to-university transfer models. In Canada, education is primarily the remit of the provincial and territorial governments. Therefore, in this literature survey, 
we have privileged literature from Canada, and particularly from the province of Ontario (where the University of Ottawa is located). However, we have included literature pertaining to other geographic regions in cases where we feel that the insights gained could apply to the Ontario context. We feel that it is pertinent to consult the broader transfer literature because, for the most part, transfer models differ at the level of administrative processes and details, which are most often the remit of administrative staff rather than faculty members. University faculty tend to have concerns that are at a somewhat broader level (e.g., workload, autonomy). These broader issues may therefore be more generalizable, and potential solutions may be at least partially transferrable from one context to another. Therefore, we feel that is worth considering the literature on transfer that comes from other regions. However, even taking this broad approach, it should be noted that there is relatively little literature that focuses on the university faculty perspective of transfer. Nonetheless, some information on this topic can be gleaned indirectly from studies that focus on college faculty, administrators, or students. In reading this literature, we identified the following five themes that have been attributed to university faculty in the context of transfer: 1) concerns about lack of university faculty buy-in; 2) concerns about transfer students' academic readiness for university courses; 3) concerns about transfer students' social integration; 4) concerns about university bureaucracy and faculty workload; and 5) concerns about university faculty autonomy.

\section{Concerns about lack of university faculty buy-in}

As noted in the introduction, there is more transfer literature that is focused on colleges than on universities, and with regard to faculty, most of this literature explores what college professors can do to prepare students for the transfer to university (e.g., O’Donnell et al., 2018). Although the focus is mainly on college professors, there are a few authors who point out that university faculty members also have a role to play and must buy-in to the transfer process if it is to be successful. For instance, based on interviews with college professors, Kisker reports that for articulation agreements to be meaningful, there must be some actual contact between college faculty and university faculty "because otherwise it's just paperwork that's funneled back and forth, and we [professors] don't do our paperwork very well” (2007, p. 292). A similar idea is expressed by university administrators who were interviewed by Tobolowsky and Cox, one of whom describes the problem as follows: "even though we have this articulation agreement ... we don't play in the same sandbox" (2012, p. 404). Meanwhile, Andres (2001) likewise emphasizes the importance of "ongoing dialogue and articulation of teaching and learning practices at both sending and receiving institutions" (p. 65) as a requirement for facilitating a smooth transition from college to university.

To address this issue, a university administrator who was interviewed by Tobolowsky and Cox recommends getting the faculty at the receiving institution talking to the faculty at the sending institution, noting that "the more we could improve that communication [between institutions] would make it more of a seamless transition for students" (2012, p. 404). Kisker is even more specific about the need to involve faculty leaders at universities because these professors are well positioned to influence others in their department, and she relays the following comments from an interview with a university administrator:

If you don't have their [faculty] buy-in, you're not going to get anywhere. And so trying to coddle, that is real critical and important .... .You've got to have the faculty vice president ... but even more so you've got to talk to department chairs (2007, p. 293).

\section{Concerns about transfer students' academic readiness for university courses}

Given that the two types of institution offer different types of courses, the question of whether students coming from college are prepared for entering university courses crops up regularly in the literature. For instance, O’Donnell et al., who investigated the perceptions of college faculty 
regarding the readiness of students for transfer programs, find that "several respondents were concerned that pathway students lacked the writing, research and referencing skills as well as the theoretical foundation for degree-level study" (2018, p. 7). Although this study reports on the perception of college faculty, rather than university faculty, there is indirect evidence to suggest that this opinion is shared by university faculty. For instance, in their interviews with university administrators, Tobolowsky and Cox (2012) report that many of them spoke of a campus-wide stereotype of transfer students being underprepared academically.

Meanwhile, as part of their investigation into the experiences of students enrolled in integrated collaborative college-university programs in Ontario, Landeen et al. (2017) report that some of the transfer students felt stigmatized because they believed that university faculty perceived them as less capable than students who had entered directly into a university program. Indeed, some students reported overhearing university faculty remark that students in collaborative college-university programs have more challenges academically than university-only students (Landeen et al., 2017).

Similarly, Andres, who investigates the experiences of transfer students in British Columbia, Canada, reports that students arriving from college found the university learning environment to be more challenging (e.g., the volume of work was higher, class sizes were larger, guidelines were less clear, and more independent work and initiative were expected), noting that "some [transfer students] were very critical of the attitudes of university professors relative to college instructors. Professors were occasionally perceived to be distant, inaccessible, and bound by fewer expectations to be clear and communicative" (2001, p. 59).

So while there seems to be indirect suggestion - reported by college professors, university administrators, and transfer students - that university faculty perceive that students coming from community colleges are not well prepared for university courses, is there evidence to support this? Percival et al. (2016) and DeWine et al. (2017) both summarize a number of studies which suggest that students transferring from colleges to universities experience an initial drop in their grades upon arrival at the university, a phenomenon referred to as transfer shock. However, there is also a growing body of evidence to indicate that these students bounce back after a semester or two (e.g., Stewart \& Martinello, 2012). In the previously mentioned study by O'Donnell et al. (2018), even though the college professors who were interviewed perceive that pathway students were less skilled in areas such as writing, research and foundational content than their non-pathway peers, this turned out not to be the case as an analysis of student grades and academic standing showed that pathway students compared favorably to their peers. However, in cases where students do experience transfer shock, Andres (2001) reports that sometimes these students associate the drop in grades with limited or unsatisfactory contact with university professors.

\section{Concerns about transfer students' social integration}

With regard to transfer students' readiness for university, most of the literature focuses on their academic preparedness (e.g., Gerhardt \& Masakure, 2016; Stewart \& Martinello, 2012); however, a burgeoning interest is being shown in better understanding their social readiness also (e.g., Flaga, 2006; Rhine, Milligan, \& Nelson; Tobolowsky \& Cox, 2012). While many of those discussions focus on transfer students' own ability to integrate with their peers at university, some of the discussions touch on faculty. For instance, Percival et al. comment that "students' perception of the quality and strength of their relationships with faculty were significantly associated with the students' academic integration at the university and self-reported personal intellectual growth" (2016, p. 24).

Meanwhile, Percival et al. report that "college students claimed that college faculty are inclined to be more involved and interested in their students' education than are university faculty" $(2015$, p. 403$)$. This echoes previous findings by Townsend and Wilson (2006), who discovered that students transferring from college frequently felt unprepared for the larger class sizes at university, and this in turn resulted in them feeling anonymous and isolated. According to Rhine et al., "faculty should be apprised of general transfer information, so they can be more helpful to students," (2000, p. 451) while 
Townsend and Wilson suggest that university faculty "should be encouraged to use pedagogical techniques to enable students to get to know at least a few students in the class. For example, students could pair off occasionally to discuss a point or answer a conceptual question” (2006, p. 453).

\section{Concerns about university bureaucracy and faculty workload}

Percival et al. state that "in Canada, college-to-university and university-to-college transfers are complicated by a confusing set of regulations that vary from province to province and from one institution to another" (2016, p. 22). In the province of Ontario more specifically, Arnold indicates that "No course-by-course (universal) transfer guide exists. [...] Credit-by-credit transfer is unorganized; institutions form rules for transfer with no measuring stick or standards" (2011, pp. 6-7). There are numerous reports of frustration on the part of students, administrators, and college professors caused by inconsistent, confusing or incorrect information being distributed about transfer programs (Andres, 2001; Arnold, 2011; Carter, Coyle, \& Leslie, 2011; Percival et al., 2016), or about information being simply too hard to find (Gerhardt \& Ackerman, 2014). When describing the situation in the European Higher Education Area, Fernández Díaz et al. (2010) comment that the provision of appropriate information is one of the most fundamental strategies that help to foster a positive attitude toward change among faculty. It is likely that a similar strategy could prove helpful in other regions also.

Related to this is the lack of consistency in terminology, noted by both Percival et al. (2016) and Kennepohl, the latter of whom insists on the need for pathway programs to be described "in a common language that is understood by both sending and receiving institutions" (2016, p. 155). Meanwhile, with regard to the impenetrability of the information describing the transfer process, this is even more pronounced for those with an additional language barrier (e.g., non-native speakers), who have found that "transfer applications and directions were often too difficult to comprehend" (Arnold, 2011, p. 12).

It seems reasonable to surmise that if all the other parties - that is, students, college professors, and administrators - find this situation to be frustratingly bureaucratic and confusing, then university faculty will probably feel likewise. One reason that faculty are reluctant to become involved in what is perceived to be a bureaucratic undertaking is because they are already busy people. As pointed out by Kirby,

There are often few incentives to encourage faculty to spend time on inter-sectoral activities. [...] university faculty spend fewer hours in the classroom [than college faculty] but face significant time pressures due to the multiple demands to teach and advise graduate students, keep up demanding scholarly commitments to academic research and peer-review publications, and perform service to their institution - all within the competitive structure of university tenure and promotion systems. The time commitment required to maintain effective collaborative programs has important implications for faculty delivering the programs. If allowances are not made in light of these pressures, the programs can compel university faculty to sacrifice scholarly research and publication obligations in favour of carrying out the administrative planning and co-ordination functions necessary to supporting collaborations (2007, p. 41).

Similar thoughts are expressed by Kisker, who observes that,

the structural and organizational barriers that restrict how much time faculty have for transfer activities result in a handful of faculty and a couple of administrators who really believe in [transfer], but most people just go about doing their jobs without a sense of this as being a mission ((2007, p. 293).

Kisker goes on to insist that the involvement of faculty from both colleges and universities is essential to the success of articulation agreements, but she laments that "unfortunately, even faculty who are interested in becoming involved in transfer activities are often precluded from doing so because of heavy course loads and other responsibilities" (2007, p. 298).

Kennepohl emphasizes that the ability for a learner to have prior academic work evaluated and recognized for transfer credit is an important part of a functioning postsecondary system that promotes seamless learner pathways; however, he readily concedes that "establishing to what degree 
two courses are equivalent is not a trivial exercise" (2016, p. 153). This is echoed by Carter et al. who decry the "cumbersome transfer methods that involve lengthy course-by-course comparisons and numerous, complicated articulation agreements, necessitating extensive investments of time for faculty" (2011, p. 20). Meanwhile, Kisker puts forward solutions such as "support, through stipends or release time" (2007, p. 298) to allow for faculty involvement in the development or maintenance of partnership pathway programs; however, such solutions may be perceived by administrators as being too costly. Meanwhile, Kennepohl (2016) and Carter et al. (2011, p. 20), among others, discuss the potential of program learning outcomes as a means to facilitate articulations; however, Kennepohl (2016, p. 159) specifically advises that whatever approach is adopted for transfers, whether it be learning outcomes or some other mechanism, it must be sensitive to workload:

any process considered should be efficient, funded, and kept at a manageable level. Faculty already provide their time through internal committee work and volunteer externally reviewing papers or contributing to their own profession. They are more likely to participate if the task is not onerous and they see value in it.

\section{Concerns about university faculty autonomy}

Finally, another concern that has been raised is the question of autonomy in the classroom. In Kisker's interviews with college faculty about transfer, she learned that when a project is being championed by the institution, a "major barrier was the attitude of faculty feeling that they were being told what to do" (2007, p. 290). If this applies to college professors, we can reasonably surmise that university faculty would feel similarly.

Meanwhile, in Kennepohl (2016), the issue of autonomy is broached in the context of a discussion about the potential of learning outcomes to facilitate credit transfer. Kennepohl (2016, p. 154) observes that "in Canada the adoption of learning outcomes has been slow at the university level," in part because it represents a substantive change in the usual business for universities. He notes that this approach is better understood in professional programs associated with professional organizations whose member certification requirements state learning outcomes; however, this approach is less well understood by many types of university programs. The question of autonomy comes up because learning outcomes can be found at the institutional, program, and course level and should be consistently linked with one other. However, Kennepohl (2016, p. 158-159) observes that while faculty tend to be supportive of learning outcomes at the institutional and program level, they become more sensitive at the course level where it might infringe on their own teaching.

\section{What do university faculty think? Survey and interviews with faculty members}

As a follow up to the literature review, we sought to engage with regular full-time faculty members at the University of Ottawa via a survey and follow-up interviews in order to gather more directly information regarding their experiences with and/or attitudes toward articulation agreements and student transfer from college to university.

\section{Background and institutional context}

A main motivation for conducting this investigation was the fact that, although the University of Ottawa is one of Canada's largest universities with approximately 35,000 students and over 600 undergraduate programs (University of Ottawa, 2018), by early 2019 , there had only ever been a total of 24 articulation agreements developed with college programs, and some of these had lapsed while others attracted very low numbers of transfer students. Moreover, although there are 24 community colleges in the province of Ontario, the University of Ottawa had only ever partnered with four of them to create pathway programs to enable students to transfer from college to university. 
This situation of limited engagement in a culture of transfer is not unique to the University of Ottawa and can be traced in part back to decisions that were made by the Ontario provincial government in the 1960s not to combine technical and general education in the same institution, but rather to establish separate colleges that concentrated on technical education. This set up a sort of competition between community colleges and universities:

When the Ontario college system was established, articulation was explicitly rejected as a goal, and that rejection prevented the development of any significant interaction between the two sectors [colleges and universities] for nearly a quarter century. What is more, it resulted in the creation of attitudinal barriers to articulation that have persisted even after the government has begun to give strong encouragement to articulation (Skolnik, 1995, p. 449).

In spite of the potential for complementarity, a competitive attitude developed between the two types of institution, which only worsened as colleges sought to award bachelor's degrees. As noted by Skolnik, "in almost all cases where community colleges have sought to offer baccalaureate programs, universities have opposed the move, viewing it as an inappropriate and hostile incursion into their jurisdiction" (2011, p. 368). Meanwhile, in the words of Urquhart, "In Ontario, there has been open conflict over territory between the universities and community colleges since the colleges obtained the authority to award baccalaureate degrees" (2004, p. A29).

With specific regard to faculty, Skolnik observes that "despite several commonalities between university and community college professors, the two remain distinct professional groups in some important ways" (2011, p. 356). He goes on to note that while both groups teach, there are differences in the type of teaching, suggesting firstly that some of the teaching done by college professors is not at a postsecondary level, and secondly that most community college professors concentrate on teaching vocationally oriented courses while the majority of university professors deliver courses that are more academic in nature and are at a higher level. As a result, Skolnik argues, a sort of hierarchical relationship has developed in which,

the perception within the universities would likely be that community college occupational courses are lower on the knowledge hierarchy because there is less abstract or theoretical content, and because admissions requirements are lower in terms of the types of secondary school courses students are expected to have earned (2011, p. 357).

In addition to the differences related to teaching, another difference between faculty at colleges and universities is in relation to research. For university faculty, research is a major activity that takes up the same proportion of their time as teaching. In contrast, community college professors are not generally expected to do research, and even those who want to often find that their substantial teaching loads and lack of institutional support make it challenging for them to do so. In the words of Urquhart, there is a "cultural gap" between the two groups in Ontario (2004, p. A29).

According to Skolnik (2011), what had been a relatively stable division of jurisdiction between these two different professional groups began to be disrupted when colleges sought to offer bridging programs - and possibly even bachelor's degrees - throwing the two groups into clear competition. According to Skolnik, the general response of universities was to set up a relationship of subordination:

Subordination enables a profession to offload some of its less glamorous or more repetitive activity to others as long as there are other professions that are willing to perform this work - while retaining the more interesting and prestigious tasks for itself. [...] What made the community college subordinate to the university was the latter's control over the awarding of credit toward bachelor's degrees for courses taken in the former (2011, p. 362).

Although these observations have been made at the institutional level and did not involve consulting individual university professors to seek direct information about their opinions or attitudes toward college professors, it is not difficult to envisage that some of the university's institutional attitude of competition or hierarchical superiority could trickle down to the faculty members themselves, 
resulting in them being somewhat resistant, as a group, to the idea of accepting transfer credits and students from colleges.

In an attempt to redress this situation, the Ontario Council on Articulation and Transfer (ONCAT) was created in 2011 "to enhance academic pathways and reduce barriers for students looking to transfer among Ontario's public colleges and universities" (ONCAT, 2019a). ONCAT offers competitive funding to institutions seeking to improve to student mobility from college to university, and the University of Ottawa's Office of the Vice-Provost, Academic Affairs, was motivated to encourage faculty members to apply to the ONCAT Faculty Fellows program with a view to carrying out a project to investigate what obstacles might be present at the university that were contributing to the low interest in articulation and transfer. The present author was subsequently named as one of six faculty fellows in the province of Ontario for 2018-2019, and this study was carried out during the fellowship period (ONCAT 2019b). While this particular investigation focused on just a single institution, we believe that the findings will be of direct interest to the other 20 universities in Ontario, as well as those in Canada's other provinces. Meanwhile, as pointed out previously, since a number of the concerns in play can be described as bigger picture issues, the findings may be broadly applicable in other regions as well.

\section{Method and instruments}

At the University of Ottawa, undergraduate programs are delivered by academic units housed in nine disciplinary Faculties: Arts, Education, Engineering, Health Sciences, Law, Management, Medicine, Science, and Social Sciences. We used the tool Survey Monkey to prepare an online survey that could be distributed to faculty members. The link to the survey was then sent to the ViceDean of Undergraduate Studies in each of the nine Faculties with the request that each Vice-Dean identify professors in their Faculty who would be well placed to respond (e.g., those who were involved in past or current articulated programs, those who had expressed interest in developing such programs, or those who belonged to units where the Vice-Dean identified potential opportunities to explore articulated programs). The survey ran during the last two weeks of March 2019.

The survey contained 15 questions, the first five of which gathered basic demographic information (i.e., Faculty, department and program) and an indication of which college partners and programs were of interest. Next, the survey sought to establish to which of the following categories the respondent's academic unit belonged: 1) currently has, 2) is developing, 3) previously had, 4) previously explored having, 5) sees potential for having, or 6) sees no potential for having an articulation agreement with a college. Respondents were then directed to a set of questions that asked them to identify any real or perceived obstacles that could hinder either the development or the smooth functioning and maintenance of an articulated program. These questions were informed in large part by the literature survey. For questions regarding obstacles, respondents could pick one or more options from a list that included the following choices, or they could suggest additional obstacles not included in the list. They were also given the opportunity to elaborate on their answers.

- Lack of awareness about opportunities to develop articulation agreements

- Concerns about the "fit" of a college program with our university program.

- Difficulty finding information about the transfer process

- Difficulty understanding information about the transfer process

- Workload and/or lack of time

- Insufficient administrative support

- Insufficient support from colleagues/peers

- Insufficient support from hierarchical superiors

- Lack of and/or poor relationship with college professors

- Concerns about professor autonomy in university courses 
- Concerns about academic standards and/or the academic readiness of college students for university

- Concerns about the social readiness of college students for university

- Concerns about the ability of university professors to teach a group of students who have received different types of academic preparation

Next, respondents were asked to indicate what conditions they felt needed to be in place in order for an articulated program to succeed. Once again, they could pick one or more options from a list, as well as suggest additional criteria. They were also invited to elaborate on their response if they wished to do so. Criteria on the list included the following:

- An awareness campaign about articulation agreements and student transfer from college to university

- A strong fit between a college program and a university program

- Clear information about the transfer process

- Easy access to information about the transfer process

- Support from senior management

- Departmental buy-in

- Course release for university professors

- Professor autonomy in university courses

- Administrative support from the department/Faculty

- Specialized pedagogical training for university professors to help them better support students from colleges

- Supplementary bridging courses for transfer students

Finally, respondents were asked in an open-ended question if there was anything else that they would like to share about barriers to developing, implementing or maintaining articulation agreements with college programs, or potential solutions to overcome these obstacles.

Before submitting the survey, respondents were also invited to indicate their willingness to participate in a short unstructured follow-up interview, which would take place either in person or over the telephone in the two weeks following the survey. The goal of the interviews was to allow the researcher to follow up on responses provided in the survey, or to allow the interviewees to expand on their answers or raise additional points about transfer that were not covered by the survey.

\section{Profile of respondents}

Nineteen different professors responded to the survey, and these respondents came from 15 different academic units housed in eight of the nine disciplinary Faculties as illustrated in Table 1.

Although the response rate might appear to be unbalanced, it is worth noting that there is considerable variation across these Faculties with regard to the number of academic units in each. For instance, the Faculty of Arts has 16 different academic units, followed by the Faculty of Social Sciences with nine academic units, then the Faculty of Health Sciences and the Faculty of Science which both have five, and the Faculty of Engineering with four. Meanwhile, the Faculties of Law, Education, and the Telfer School of Management are faculties that do not have any internal division into academic units. The only Faculty with no respondents was the Faculty of Medicine, which is understandable given that admission to the undergraduate medical education program requires the prior completion of three years of full-time university study. Therefore, while we did not manage to get information from every Faculty or academic unit, we did manage to cover a reasonable cross section of the university by gathering 19 responses from 15 different academic units in eight different Faculties. 
Table 1. Academic units that participated in the survey and interviews.

\begin{tabular}{|c|c|c|c|}
\hline Faculty & Academic Units & $\begin{array}{l}\#(\%) \text { of survey } \\
\text { respondents }\end{array}$ & $\begin{array}{l}\text { \# (\%) of interview } \\
\text { respondents }\end{array}$ \\
\hline Arts & $\begin{array}{l}\text { Communication (3); English; Music; Theater; } \\
\text { Translation }\end{array}$ & $7(37 \%)$ & $4(40 \%)$ \\
\hline Law & Law & $1(5 \%)$ & $1(10 \%)$ \\
\hline Education & Education & $1(5 \%)$ & $1(10 \%)$ \\
\hline Engineering & $\begin{array}{l}\text { Civil Engineering; Electrical Engineering; Mechanical } \\
\text { Engineering }\end{array}$ & $3(17 \%)$ & $1(10 \%)$ \\
\hline Medicine & - & 0 & 0 \\
\hline Science & Chemistry & $1(5 \%)$ & 0 \\
\hline Health Sciences & Human Kinetics; Nursing (2); Nutrition Sciences & $4(21 \%)$ & $2(20 \%)$ \\
\hline Social Sciences & Economics & $1(5 \%)$ & 0 \\
\hline Telfer & Management & $1(5 \%)$ & $1(10 \%)$ \\
\hline Total & & $19(100 \%)$ & $10(100 \%)$ \\
\hline
\end{tabular}

At the end of the survey, respondents were asked to indicate whether they would be willing to participate in a follow-up interview. Ten of the 19 respondents agreed to be interviewed, and these participants came from seven different academic units housed in six different Faculties (Arts, Education, Engineering, Health Sciences, Law, and Management), as summarized in Table 1. Of the ten interviews, eight were conducted via telephone and two were conducted in person, according to the preferences of the respondents. The length of the unstructured interviews ranged from five to fifteen minutes in length.

Overall, while the number of survey respondents (19) and interviewees (10) was modest, the participants nonetheless represented a good cross-section of disciplinary cultures at the university. In addition to obtaining disciplinary diversity, we also successfully obtained information from respondents who had different types or levels of experience with articulation agreements and transfer. For instance, we managed to obtain both survey responses and interviews with respondents from each of the six previously mentioned categories with regard to the status of an articulated program; these are summarized in Table 2. Moreover, the responses covered experiences with four different community colleges in total.

\section{Survey results}

As previously described, a main focus of the survey questions was to identify barriers (whether actual or anticipated) relating to the development of articulation agreements, as well as obstacles (actual or anticipated) relating to the smooth functioning and maintenance of articulation agreements. In addition, respondents were also asked to reflect on what conditions they felt would need to be in place in order to set an articulated program up for success.

With regard to responses, the number of survey respondents who identified concerns about different obstacles for developing and maintaining articulated programs with college partners are summarized in Table 3. Meanwhile, Table 4 presents a summary of the conditions that survey respondents deemed to be important in order to set an articulated program up for success.

Table 2. The status of articulated programs.

\begin{tabular}{lcc}
\hline The academic unit ... & \# of survey respondents & \# of interviewees \\
\hline$\ldots$ currently has an articulated program & $7(37 \%)$ & $3(30 \%)$ \\
$\ldots$ is in the process of developing an articulated program & $1(5 \%)$ & $1(10 \%)$ \\
$\ldots$ previously had an articulated program but it is no longer functioning & $2(11 \%)$ & $2(20 \%)$ \\
$\ldots$ previously explored having an articulated program & $2(11 \%)$ & $1(10 \%)$ \\
$\ldots$ sees potential for developing an articulated program & $1(5 \%)$ & $1(10 \%)$ \\
$\ldots$ sees no potential for developing an articulated program & $6(31 \%)$ & $2(20 \%)$ \\
Total & $19(100 \%)$ & $10(100 \%)$ \\
\hline
\end{tabular}


Table 3. Obstacles to the development and maintenance of articulated programs.

\begin{tabular}{lcc}
\hline & $\begin{array}{c}\text { \# (\%) respondents who } \\
\text { identified this as } \\
\text { a concern for developing } \\
\text { an articulated program }\end{array}$ & $\begin{array}{c}\text { identified this as } \\
\text { a concern for } \\
\text { maintaining an } \\
\text { articulated program }\end{array}$ \\
Obstacles & $3(16 \%)$ & N/A \\
\hline Lack of awareness about opportunities to develop articulation agreements & $10(53 \%)$ & $7(37 \%)$ \\
Concerns about the fit of a college program with our university program. & $2(11 \%)$ \\
Difficulty finding information about the transfer process & $2(11 \%)$ & $2(11 \%)$ \\
Difficulty understanding information about the transfer process & $7(37 \%)$ & $6(32 \%)$ \\
Workload and/or lack of time & $3(16 \%)$ & $4(21 \%)$ \\
Insufficient administrative support & $5(26 \%)$ & $3(16 \%)$ \\
Insufficient support from colleagues/peers & $2(11 \%)$ & $2(11 \%)$ \\
Insufficient support from hierarchical superiors & 0 & $3(16 \%)$ \\
Lack of and/or poor relationship with college professors & $1(5 \%)$ & $3(16 \%)$ \\
Concerns about professor autonomy in university courses & $12(63 \%)$ & $7(37 \%)$ \\
Concerns about academic standards and/or the academic readiness of & $1(5 \%)$ & 0 \\
college students for university & $1(5 \%)$ & 0 \\
Concerns about the social readiness of college students for university & $9(56 \%)$ & $6(32 \%)$
\end{tabular}

As Table 3 indicates, the three most frequently cited concerns for both developing and maintaining an articulation agreement are:

(1) concerns about academic standards and/or academic readiness of college students for university (identified as a concern by $63 \%$ of respondents for developing articulation agreement and by $37 \%$ of respondents for maintaining an agreement);

(2) concerns about the fit of a college program with the university program (53\% for developing and $37 \%$ for maintaining); and

(3) concerns about faculty workload and/or lack of time (37\% for developing and $32 \%$ for maintaining).

If we refer back to the information gleaned from the literature review, we can recall that all three of these concerns also featured prominently in the literature on transfer. Meanwhile, workload also came up in another way as part of the survey; as shown in Table 4, when asked to identify conditions that would help to set an articulation agreement up for success, $58 \%$ of respondents indicated that it would be important to have administrative support from the academic unit or Faculty, while $32 \%$ of

Table 4. Conditions that need to be in place to set an articulated program up for success.

\begin{tabular}{lc} 
Conditions & $\begin{array}{c}\#(\%) \text { of } \\
\text { respondents* }\end{array}$ \\
\hline An awareness campaign about articulation agreements and student transfer from college to university & $7(37 \%)$ \\
A strong fit between a college program and a university program & $19(100 \%)$ \\
Clear information about the transfer process & $5(26 \%)$ \\
Easy access to information about the transfer process & $6(32 \%)$ \\
Support from senior management & $8(42 \%)$ \\
Departmental buy-in & $10(53 \%)$ \\
Course release for university professors & $6(32 \%)$ \\
Professor autonomy in university courses & $6(32 \%)$ \\
Administrative support from the department/Faculty & $11(58 \%)$ \\
Specialized pedagogical training for university professors to help them better support students from & 0 \\
colleges & $6(32 \%)$ \\
Supplementary bridging courses for transfer students & $1(5 \%)$
\end{tabular}

*Faculty who feel this is important to set an articulated program up for success. 
respondents advocated for course release for professors involved in setting up and overseeing transfer programs.

We can observe other survey responses that also correspond to concerns in the literature. For instance, the literature on transfer emphasized the importance of having faculty buy-in, and in our survey, respondents identified insufficient support from colleagues/peers as being an obstacle for both the development (26\%) and maintenance (16\%) of articulation agreements (see Table 3). In addition, in response to the question about what conditions need to be in place in order to set an articulated program up for success, $53 \%$ of respondents identified departmental buy-in as an important criterion (see Table 4). Meanwhile, in a similar vein, the literature on transfer emphasized the value of institutional support. In Table 3, insufficient support from hierarchical superiors was identified as a barrier by $11 \%$ of respondents with regard to both the development and the maintenance of articulation agreements. However, having support from senior management was also selected by $42 \%$ respondents as being a key condition for setting up an articulated program for success, as illustrated in Table 4.

The literature on transfer identified professor autonomy as a key factor, and while this was mentioned as an obstacle to developing an articulation agreement by only $5 \%$ of respondents and as an obstacle to the maintenance of an agreement by just $16 \%$ of respondents (see Table 3), it was also identified by $32 \%$ of respondents as being an important criterion for setting an articulated program up for success (see Table 4).

The benefits of raising awareness and visibility of transfer came out in the literature. Likewise, in our survey, $16 \%$ of respondents noted that lack of awareness about opportunities to develop articulation agreements presented an obstacle to establishing such agreements (see Table 3), while $37 \%$ of respondents suggested that an awareness campaign about articulation agreements and student transfer was something that could help to set an articulated program up for success (see Table 4).

In contrast, some of the issues that were flagged in the literature as areas of concern did not appear to trouble the survey respondents too greatly. For instance, the literature discussed concerns about college students' social readiness for university; however, these concerns did not feature heavily among the survey responses. For instance, as illustrated in Table 3, just a single respondent (5\%) identified concern about college students' social readiness for university as an obstacle to developing an articulated program, while no respondents selected this as a concern during the maintenance of an articulation agreement.

Similarly, problems relating to bureaucracy surrounding the transfer process, including opaque language being used to explain it, were discussed regularly in the literature on transfer. However, as reported in Table 3, in our survey, only $11 \%$ of respondents said that difficulty finding information about the process was an issue at both the development and maintenance stages, and likewise, just $11 \%$ indicated that difficulty understanding information about the process was an obstacle at both the development and maintenance stages. Interestingly, however, when asked about conditions that are necessary to ensure the success of an articulated program, over a quarter (26\%) of respondents indicated that it is important to have clear information about the process and nearly one third (32\%) emphasized that the information must be easily accessible, as illustrated in Table 4. Therefore, while respondents feel that these are somewhat important conditions, it would appear that they are being met reasonably well by the University of Ottawa at the present time.

Another issue that did not emerge from the literature review but which was raised in the Other option was the challenge of developing an articulation agreement for a program that must undergo an external professional accreditation. This issue was raised by six different respondents, and was explored in more depth during the interviews.

\section{Interview results}

The ten interviews were unstructured and were intended to provide respondents with an opportunity to share any other comments that they wished to share about their experience exploring, developing, 
maintaining or discontinuing articulation agreements, or indeed any other thoughts on the topic of transfer and student mobility in general. In some cases, respondents used this as an opportunity to reinforce or expand on one or more of their selected answers to a survey question, while in other cases, new points that were not well addressed by the specific survey questions were introduced. Therefore, the follow-up interviews - even the short ones - proved valuable because they allowed us to gain a deeper understanding of issues that were overlooked or noted only briefly in the survey responses, or which of the multiple options selected were considered to be the most important. For instance, although the survey did not ask respondents to rank the importance of the options they chose, a five-minute interview provided enough time for them to indicate which they considered to be more significant and which were less important.

One issue that had not been well addressed as part of the survey was the challenge posed for a program that has an external accreditation requirement. Interviewees from three different programs raised this issue. According to these three interviewees, the externally imposed accreditation requirements of some professional associations made it challenging to develop collaborative programs. An example given by one participant was that the professional association expected courses to be taught by instructors with a certain type of qualification that is common among university professors working in this subject area but is less common among college professors. Meanwhile, another participant indicated that the competences required by the accrediting body were very strict and that college-level courses were not always taught at a sufficiently advanced level to meet these requirements. However, another interviewee suggested that while this might at first appear as a challenge, it could in fact be seen as an opportunity to invite representatives from the relevant professional association to participate in the development of the articulated program.

On another topic, one interviewee expressed surprised at having been invited to participate in the survey/interview, noting that to the best of their knowledge, no college had ever expressed an interest in developing a transfer agreement with any unit in their Faculty. In the interview, it was revealed that the interviewee had never considered that such an initiative could be proposed by a university partner rather than by a college partner. Meanwhile, another interviewee stated that there was no shortage of students entering their university program directly, and that they would likely be motivated to explore an articulation agreement only if they had low enrollments and were seeking more students. In contrast, another interviewee registered surprise that there was not a more coordinated effort on the part of the university to encourage transfer and mobility between college and university, noting that some leadership and encouragement could be helpful. This interviewee suggested that the Vice-Deans of Undergraduate Studies in the various Faculties would do well to pro-actively meet with the Heads of academic units to explore and/or promote the option of articulation agreements.

A related notion was expressed by another interviewee, who noted that administrative support to promote the agreements and to do follow-ups with the colleges would be appreciated. In this case, a transfer pathway was in place but the number of students who took it up was quite low, causing frustration for the professors who had invested so much time and energy to set it up. This general idea was echoed by a second interviewee who noted that setting up a program was one thing, but making it work was quite another, and by a third who commented on the low "return on investment" (i.e., few students actually taking advantage of the articulation agreement once it had been set up). All three of these interviewees emphasized that professors could only be expected to do so much with regard to recruitment, and that the institution needed to provide greater support in this regard to make these initiatives successful.

Low enrollments were seen as a risk by several other interviewees also. However, one of them liked the idea of the programs being somewhat selective rather than having a mass appeal, noting that the most successful transfer students were the ones who had been identified by the college partner as being particularly good candidates and had then been actively encouraged to make the transfer. This interviewee wished there could be a more formal mechanism for colleges to identify and recommend specific students that they think are well suited for transfer. 
The importance of finding a good fit between college and university programs - and the challenge of doing so - came up frequently in the interviews as it did in the survey, and it was emphasized by most interviewees as being the overriding concern. In the case of one interviewee, this was articulated more specifically as being a concern about skills vs knowledge, with the interviewee expressing the opinion that college programs emphasized skills whereas universities emphasized knowledge, and that when students transferred from college programs, they had missed out on some of the foundational knowledge. This same interviewee went on to note that course descriptions from the two institutions may look very similar on the surface, but upon closer inspection, the courses may actually be quite different. For this reason, the interviewee recommended going beyond the course descriptions and actually investigating the profile of the professors, as well as the specific textbooks used, noting that the college textbooks are more often "how to" manuals, while the university textbooks focus more on the underlying science. Another interviewee commented that a former articulation agreement had to be canceled because a change in admission requirements to the bachelor's program meant that the college courses were no longer considered as being able to meet these requirements. Meanwhile a different interviewee commented that the articulated program only functioned well if the college students went on to choose "appropriate courses" at the university level, and that problems arose when transfer students took on elective courses for which they had not been well prepared.

\section{Discussion}

Because this project was carried out on a small scale at just one institution, the results cannot necessarily be generalized. Nonetheless, this investigation has resulted in some useful findings for the University of Ottawa that may potentially also provide insights into the university faculty perspective at other institutions. In addition, it could potentially serve as a model that could be adopted or adapted by other universities that wish to investigate the faculty perspective on transfer and mobility at their own institution.

In general, the survey and interviews revealed that the principal concerns expressed by the participants correspond largely to those raised in the literature on transfer. The top three concerns that came out of the surveys/interviews include concerns about academic standards and/or academic readiness of college students for university; concerns about the fit of a college program with the university program; and concerns about faculty workload and/or lack of time. Moreover, these concerns were expressed both by respondents whose programs had actual experience of participating in articulation agreements and by those whose programs were simply exploring the possibility.

Correction of misassumptions is one way to counteract the notion held by some faculty that transfer students are not academically ready for university courses. As illustrated by Stewart and Martinello (2012), DeWine et al. (2017), and O'Donnell et al. (2018), among others, while transfer students may initially experience transfer shock during which their grades initially decline, they often bounce back relatively quickly and go on to perform as well as or better than students who have entered university directly. Andres submits that educating faculty members is key to warding off false perceptions that transfer students are collectively weaker than direct entry university students, and she suggests that “efforts designed to raise instructors' awareness of teaching and learning problems encountered by transfer students at both community colleges and universities may help to mitigate the magnitude of 'transfer shock' experienced by students" (2001, p. 65). Meanwhile, DeWine et al. point to:

the need for faculty collaboration between community colleges and universities to improve the transfer-student transition process, including the exchange of course syllabi from the transfer institutions, comparing curriculum content, and jointly defining the expected knowledge and skills at the 4 -year institution. (2017, p. 810)

Finally, although the literature suggested that bureaucracy could be an issue impeding access to and understanding of documents associated with the process of developing and maintaining articulation agreements, this did not appear to be a significant obstacle for faculty members at the University of 
Ottawa. However, it was mentioned by numerous respondents that an awareness campaign about opportunities could be a valuable undertaking. In contrast, numerous respondents indicated that additional support from the university - such as in the form of marketing an articulated program, and administrative support for managing an articulated program - could contribute greatly to a program's success.

\section{Conclusion}

The university faculty perspective is one that has been under-investigated to date. Though conducted on a small scale, our investigation was nonetheless useful because it revealed that faculty do indeed have opinions and concerns about transfer, and while some of these correspond to indirect observations made about university faculty by other transfer stakeholders (e.g., college professors, college and university staff and administrators, and transfer students), others diverge from what has been reported by these other parties. Therefore, it would seem worthwhile to consult university faculty directly on a wider scale to get a better handle on the concerns that they have so that these might be appropriately addressed in order to increase the success of articulation agreements and transfer programs. By engaging with university faculty about their apprehensions, it is possible that these concerns could be mitigated, thus increasing transfer opportunities and improving transfer experiences.

In addition, by consulting faculty directly about their needs, universities can direct both human and financial resources more appropriately for maximum impact. For instance, at the University of Ottawa, faculty seem relatively content with the nature and accessibility of the information provided about the transfer process, so there would not seem to be a need at present to invest significantly in this area. In contrast, faculty members expressed a desire for more support in the area of marketing and recruitment to increase the uptake of existing transfer programs. They also suggested that a campaign to raise awareness about and promote a culture of transfer could be beneficial since transfer seems to have relatively low visibility on the campus. Therefore, these could potentially be areas where the University of Ottawa could meaningfully invest additional resources. Indeed, these are recommendations that we have already passed along to the Office of the Vice-Provost, Academic Affairs, who are consequently planning an information session and workshop for the coming academic year, which will involve not only university faculty, but also college faculty.

While the needs at other institutions may differ from those that we have identified at the University of Ottawa, the important takeaway here is that university faculty do indeed have thoughts about transfer and are open to being engaged on the subject. The most effective way to find out what they are thinking is to ask them. We hope this article will inspire more universities to do just that.

\section{Funding}

This work was supported with a grant from the Ontario Council on Articulation and Transfer (ONCAT) as part of their [2018-2019 Faculty Fellows program].

\section{ORCID}

Lynne Bowker (1D) http://orcid.org/0000-0002-0848-1035

\section{References}

Andres, L. (2001). Transfer from community college to university: Perspectives and experiences of British Columbia students. Canadian Journal Higher Education, 31(1), 35-74.

Arnold, C. H. (2011). Following the Ontario transfer student: From college to university inception. Canadian Society for the Study of Higher Education, Professional File, 31, 1-19. Retrieved from http://csshescees.files.wordpress.com/ 2014/03/pf_31_arnold.pdf 
Carter, I., Coyle, J., \& Leslie, D. (2011). Easing the transfer of students from college to university programs: How can learning outcomes help? Canadian Journal of Higher Education, 41(2), 10-27.

DeWine, P. R., Bresciani Ludvik, M., Tucker, M., Mulholland, S., \& Bracken, W. (2017). Exploring a successful community college student transition to a research-university environment. Community College Journal of Research and Practice, 41(12), 809-822. doi:10.1080/10668926.2016.1232669

Fernández Diaz, M. J., Carballo Santaolalla, R., \& Galán González, A. (2010). Faculty attitudes and training needs to respond to the new European higher education challenges. Higher Education, 60(1), 101-118. doi:10.1007/s10734009-9282-1

Flaga, C. T. (2006). The process of transition for community college transfer students. Community College Journal of Research and Practice, 30(1), 3-19. doi:10.1080/10668920500248845

Gerhardt, K., \& Ackerman, M. (2014). Postsecondary student mobility from college to university: Student expectations and experience. College Quarterly, 17(1). Retrieved from http://collegequarterly.ca/2014-vol17-num01-winter/ger hardt-ackerman.html

Gerhardt, K., \& Masakure, O. (2016). Postsecondary student mobility from college to university: Academic performance of students. Canadian Journal of Higher Education, 46(2), 78-91.

Kennepohl, D. E. (2016). Incorporating learning outcomes in transfer credit: The way forward for campus alberta? Canadian Journal of Higher Education, 46(2), 148-164.

Khaja, A. F. (2013). Exploring the evolution of credit transfer policy: Implications on the role and interplay between colleges and universities (Master's thesis). University of Toronto, Canada.

Kirby, D. (2007). Change and challenge: Ontario's collaborative baccalaureate nursing programs. Canadian Journal Higher Education, 37(2), 29-46.

Kisker, C. B. (2007). Creating and sustaining community college-university transfer partnerships. Community College Review, 34(4), 282-301. doi:10.1177/0091552107300333

Landeen, J., Matthew-Maich, N., Marshall, L., Hagerman, L.-A., Bolan, L., Parzen, M., ... Shukla, B. (2017). Experiences of students enrolled in integrated collaborative college/university programs. Canadian Journal Higher Education, 47(2), 135-155.

McGowan, R. A., \& Gawley, T. (2006). The university side of the college transfer experience: Insights from university staff. College Quarterly, 9(3). Retrieved from http://collegequarterly.ca/2006-vol09-num03-summer/mcgowan_gaw ley.html

O’Donnell, J., Miller, S., \& Fowler, D. (2018). Faculty perspectives on diploma-degree pathways and student preparedness. Retrieved from http://humber.ca/strategicplanning/sites/default/files/ FullReportFacultyPerceptionsOnDiplomaDegreePathwaysAndStudentPreparedness.pdf

Ontario Council on Articulation and Transfer [ONCAT]. (2019a). About us. Retrieved from https://oncat.ca/en/about-us

Ontario Council on Articulation and Transfer [ONCAT]. (2019b). Faculty fellows. Retrieved from https://www.oncat. ca/en/faculty-fellows

Percival, J., DiGiuseppe, M., Goodman, B., LeSage, A., Hinch, R., Samis, J., ... De La Rocha, A. (2015). Exploring student and advisor experiences in a college-university pathway program: A study of the bachelor of commerce pathway. Canadian Journal Higher Education, 45(4), 400-422.

Percival, J., DiGiuseppe, M., Goodman, B., LeSage, A., Longo, F., De La Rocha, A., ... Raby, P. (2016). Exploring factors facilitating and hindering college-university pathway program completion. International Journal of Education Management, 30(1), 20-42.

Rhine, T. J., Milligan, D. M., \& Nelson, L. R. (2000). Alleviating transfer shock: Creating an environment for more successful transfer students. Community College Journal of Research and Practice, 24(6), 443-453. doi:10.1080/ 10668920050137228

Senie, K. C. (2016). Implementing transfer and articulation: A case study of community colleges and state universities. Community College Journal of Research and Practice, 40(4), 269-284. doi:10.1080/10668926.2015.1038667

Shaw, S. T., Spink, K., \& Chin-Newman, C. (2019). "Do I really belong here?”: The stigma of being a community college transfer student at a four-year university. Community College Journal of Research and Practice, 43(9), 657-660. doi:10.1080/10668926.2018.1528907

Skolnik, M. L. (1995). Evolution of relations between community colleges and universities in Ontario. Community College Journal of Research and Practice, 19(5), 437-451. doi:10.1080/1066892950190506

Skolnik, M. L. (2011). Re-conceptualizing the relationship between community colleges and universities using a conceptual framework drawn from the study of jurisdictional conflict between professions. Community College Review, 39(4), 352-375. doi:10.1177/0091552111424205

Stewart, J., \& Martinello, F. (2012). Are transfer students different? An examination of first-year grades and course withdrawals. Canadian Journal of Higher Education, 42(1), 25-42.

Tobolowsky, B. F., \& Cox, B. E. (2012). Rationalizing neglect: An institutional response to transfer students. The Journal of Higher Education, 83(3), 389-410. doi:10.1353/jhe.2012.0021

Townsend, B. K., \& Wilson, K. B. (2006). 'A hand hold for a little bit': Factors facilitating the success of community college transfer students to a large research university. Journal of College Student Development, 47(4), 439-456. doi:10.1353/csd.2006.0052 
Umbach, P. D., Tuchmayer, J. B., Clayton, A. B., \& Smith, K. N. (2019). Transfer student success: Exploring 705 community college, university, and individual predictors. Community College Journal of Research and Practice, 43 (9), 599-617. doi:10.1080/10668926.2018.1520658

University of Ottawa. (2018). Quick facts. Retrieved from https://www.uottawa.ca/institutional-research-planning /resources/facts-figures/quick-facts

Urquhart, I. (2004, November 10). Colleges, universities gird for fight. Toronto Star, p. A29.

Wheeler, E. J. (2019). Extending 'guided pathways' beyond the community college: Lessons for university transfer orientation. Community College Journal of Research and Practice, 43(4), 275-279. doi:10.1080/10668926.2018.1460283 